\title{
Study on the prevalence of bovine fasciolosis in and around Bahir Dar, Ethiopia
}

\author{
Fikirtemariam Aregay ${ }^{1}$, Jemere Bekele ${ }^{2}$, Yeshwas Ferede ${ }^{3}$ and Mussie Hailemelekot ${ }^{4}$ \\ ${ }^{I}$ Dr.fikirte Medium Veterinary Clinic, B/Dar Zuria District, Bahir Dar, Ethiopia. \\ ${ }^{2}$ Hawassa University, P.O. Box 05, Ethiopia \\ ${ }^{3}$ Andassa Livestock Research center, PO Box 27, Bahir Dar, \\ Ethiopia, yeshwasferede@yahoo.com \\ ${ }^{*}$ Corresponding author: Bahir Dar University, PO Box 79, Ethiopia, musiehailu@yahoo.com
}

\begin{abstract}
A cross sectional study aimed at determining the prevalence and type of common Fasciola species in cattle was conducted in and around Bahir Dar from November 2008- March 2009. The study was based on post-mortem inspection of livers of slaughtered animals at Bahir Dar municipality abattoir and coprological examination using sedimentation technique on fecal samples collected from animals of Bahir Dar and surrounding areas. Out of 413 livers inspected, 165 (39.95\%) were positive for Fasciola species. F. hepatica was found to be the most prevalent species in cattle of the study area $(89.70 \%)$. About $3.63 \%$ were positive for $F$. gigantica and $6.67 \%$ were harboring mixed infections. Likewise, out of 384 fecal samples examined 141 (36.72) were positive for the presence of Fasciola eggs. Risk factors such as locality, body condition and sex didn't show any effect on the prevalence of infections $(\mathrm{P}>0.05)$. However, breed and age group revealed significant disparity $(\mathrm{P}<0.05)$ as greater magnitude of infections were detected in exotic breed and young age group, respectively. In view of the current result, fasciolosis could be considered as a major problem in Bahir Dar and surrounding areas as the ecological factors and management conditions are suitable both for the snail intermediate host and the parasite to be maintained. Strategic treatments need to be implemented at appropriate timing with the aim of reducing worm burden from infected animals and preclude pasture contamination. Integrated control approaches involving livestock owners has to be implemented in reducing the population and activity of snail intermediate hosts to enable maximization of long-term returns from such endemic areas.
\end{abstract}

Key words: Abattoir, Bovine, Bahir Dar, Coprology, Fasciola, Prevalence. http://dx.doi.org/10.4314/evj.v17i1.1 


\section{Introduction}

Ethiopian livestock productivity, despite its huge population size, remains marginal due to various diseases, malnutrition and management constraints. Parasitism represents a major obstacle to the development of sub-sector (Malone et al., 1998). Bovine fasciolosis is one of the most important parasitic diseases of cattle causing mortality and production losses in various parts of Ethiopia. Fasciolosis is the priority disease in the highland as well as in lowland areas of Amhara region (Solomon Woldemariam and Abebe Wossene, 2007). The members of this genus are commonly known as liver flukes. They are responsible for widespread mortality and morbidity in cattle characterized by weight loss, anemia and hypoproteinemia. The two most important species include $F$. hepatica found in the temperate cooler areas of highland, in the tropics and subtropics and F. gigantica which predominates in tropical areas (Urquhart et al., 1996). Parasitic $F$. hepatica infects cattle and other mammalian species and is endemic in many parts of the world (Rapsch et al., 2006) and F. gigantica is the most common species found in Africa and Asia. It is recognized as major source of loss of production in domestic ruminants (Woman et al., 1998).

In Ethiopia, the prevalence of bovine fasciolosis has shown to range from $11.5 \%$ to $87 \%$ (Malone et al., 1998). F. hepatica was shown to be the most important fluke species in Ethiopian livestock with distribution over three quarter of the nation except in the arid northeast and east of the country. The distribution of $F$. gigantica was mainly localized in the western humid zone of the country that encompasses approximately one fourth of the nations (Tadele Tolossa and Worku Tigre, 2006; Malone et al., 1998).

The disease is found in vast water lodged and marshy grazing field condition anticipated to be ideal for the propagation and maintenance of high prevalence of fasciolosis. In Ethiopia, the highlands contain pockets of water logged marshy areas. These provide suitable habitats year round for the snail intermediate hosts (Solomon Woldemariam and Abebe Wossene, 2007). More rational prophylactic programs based on local epidemiological information are needed for sound fasciolosis control strategies in Ethiopia (Yilma Jobre and Malone, 1998). Though the problem due to Fasciola was reported from different parts of the country, information on the current status from different locations need to be attained. This study aims to fill such gap and hence been carried out in cattle in and around Bahir Dar. Therefore, the objectives of this work were: to study the prevalence of fasciolosis in cattle in and around Bahir Dar and to determine the common Fasciola species in the area. 


\section{Materials and Methods}

Study area

The study was conducted in and around Bahir Dar, North West Ethiopia which is located at about 654 kilometers away from Addis Ababa. The area is located at $11^{0}$ 29" N latitude and $37^{\circ} 29$ " E longitudes with an elevation of 1730 meters above sea level. About $70 \%$ of the land is featured by plain plateaus and covered by various bush formations; low woods mainly evergreen plants, and some semi-humid highland vegetation, with major agricultural products like teff, wheat, sorghum, millet, maize, and all pulse crops.

The area has a summer rainfall with mean annual rainfall and mean annual temperature of $1465 \mathrm{~mm}$ and $29.5^{\circ} \mathrm{c}$ respectively. The landscape is marked by the presence of Lake Tana, which drains a watershed of about $3,000 \mathrm{~km}^{2}$ and areas adjacent to Lake Tana and Abay river have poor drainage and annual over flooding during the rainy seasons leave pockets of water bodies, which persist during the dry months.

There are about 16.8 million inhabitants in the region of which $89 \%$ are living in the rural area. The livelihood of the peoples is based on agriculture and $80 \%$ of the population practice mixed crop livestock farming system. The region has 10.6 million cattle, 5.7 million sheep, 4 million goats, 2.1 million equines and 17,400 camels managed under extensive management system (BOA, 2000).

Study animals

Post-mortem examination and sample collection was conducted on cattle slaughtered at Bahir Dar municipality abattoir during the period of November 2008 to March 2009. About 413 male adult indigenous cattle were examined after slaughter. Cattle slaughtered in the abattoir were brought from different locations including the southern part of Gondar. Coprological examination was conducted on fecal samples directly from the rectum of live animals (of cattle) into a universal bottle and then transported to the laboratory for the presence of characteristic Fasciola eggs by direct sedimentation technique. Cattle were randomly selected for fecal sample collection from localities of Andasa, Kebele 11(Gedro) and Kebele 13.

Study design

A cross-sectional study was conducted to determine the prevalence of bovine 
fasciolosis by using both post-mortem examination of liver from each slaughtered animal and using laboratory examination employing sedimentation technique on feces collected directly from the rectum of live animals (cattle).

Sample size and sampling methods

Abattoir sampling was done on cattle slaughtered at Bahir Dar municipality abattoir during the study period. Possibly, all cattle slaughtered were examined for the presence of fasciolosis. In case of live animal sampling, the animals were selected using simple random sampling method where it was planned to include some 384 cattle. The formula given by Thrusfield (1995) is used to determine the number of cattle for sampling as follows:

$\mathrm{n}=1.96^{2} \mathrm{P}(1-\mathrm{P}) / \mathrm{d}^{2}$ where $\mathrm{p}$ - Expected prevalence d- Absolute precision

$\mathrm{n}$ - Sample size By taking $\mathrm{P}=50 \%$ and $\mathrm{d}=0.5 \%, \quad \mathrm{n}=1.96^{2} 0.5(1-0.5) /(0.0025)$ $\mathrm{n}=384$ live animal were sampled

Sampling procedures

\section{Post mortem Examination}

The liver of each slaughtered animal was carefully examined by visualization and palpation of the entire organ that was followed by transverse incision of the organ to check for the presence of adult flukes. Available adult flukes were collected in a universal bottle containing $10 \%$ formalin and then transported to the laboratory for species identification.

\section{Coprological examination}

Live animal examination was conducted on fecal samples collected directly from the rectum of cattle into a universal bottle containing $10 \%$ formalin and transported to the laboratory for examination. Sampling was carried out at random with inclusion of age, sex, breed, and body condition of animals in three localities included. The fecal samples were kept at $4{ }^{\circ} \mathrm{c}$ until all are processed and examined. Sedimentation technique was used to detect the presence of absence of fluke eggs in the fecal sample collected.

\section{Data management and analysis}

Data from the post-mortem examination and laboratory findings were entered and 


\section{Results}

Post-mortem findings

Prevalence

Out of the total 413 adult indigenous cattle slaughtered and examined in the period from November 2008-March 2009 at Bahir Dar municipality abattoir, 165 (39.95\%) were found to be positive for fasciolosis. The body condition results indicate that there was no statistically significant variation $(p>0.05)$ observed between animals having good and poor body condition with regard to occurrence of infection (Table 1).

Table 1. Prevalence of fasciolosis in slaughtered cattle at Bahir Dar municipality abattoir based on body condition

\begin{tabular}{lllll}
\hline $\begin{array}{l}\text { Body } \\
\text { Condition }\end{array}$ & $\begin{array}{l}\text { Number } \\
\text { Examined }\end{array}$ & $\begin{array}{l}\text { Number } \\
\text { Positive }\end{array}$ & Prevalence (\%) & $95 \%$ CI \\
\hline Poor & 173 & 68 & 39.30 & $31.95-46.66$ \\
Good & 240 & 97 & 40.41 & $34.16-46.67$ \\
\hline Total & 431 & 161 & 39.95 & $35.21-44.7$ \\
\hline
\end{tabular}

\section{Species composition of Fasciola}

Out of the 165 livers found positive for Fasciola infection during post-mortem inspection of slaughtered cattle, $148(89.7 \%)$ liver harboured $F$. hepatica, 6 $(3.63 \%)$ liver infected with $F$. gigantica and $11(6.67 \%)$ liver harbored mixed infections with both $F$. hepatica and $F$. gigantica species) (Table 2).

Table 2. Species composition of Fasciola detected in livers of infected cattle slaughtered at Bahir Dar municipality abattoir

\begin{tabular}{llll}
\hline $\begin{array}{l}\text { Species of } \\
\text { Fasciola }\end{array}$ & $\begin{array}{l}\text { Number of } \\
\text { livers infected }\end{array}$ & Percentage & $95 \% \mathrm{CI}$ \\
\hline F. hepatica & 148 & $89.70 \%$ & $85.00-94.38$ \\
F. gigantica & 6 & $3.63 \%$ & $0.75-6.52$ \\
Mixed infection & 11 & $6.67 \%$ & $2.82-10.51$ \\
\hline Total & 165 & $100 \%$ & \\
\hline
\end{tabular}




\section{Coprological findings}

Of the total 384 fecal samples examined from live cattle, 141(36.72\%) were positive for Fasciola eggs. There was no statistically significant variation in the prevalence of bovine fasciolosis $(\mathrm{P}>0.05)$ among the different localities (peasant associations) studied (Table 3). There was statistically significant differences between the local and cross breeds of cattle on the prevalence of fasciolosis on fecal examination results $(\mathrm{P}<0.05)$ (Table 4$)$.

Table 3. Prevalence of bovine fasciolosis in live cattle on locality basis

\begin{tabular}{lllll}
\hline Locality & Sample size & Positive & $\begin{array}{l}\text { Prevalence } \\
(\%)\end{array}$ & $95 \%$ CI \\
\hline Andassa & 124 & 46 & 37.09 & $28.48-45.72$ \\
Kebele 11 (Gedro) & 130 & 48 & 36.92 & $28.52-45.33$ \\
Kebele 13 & 130 & 47 & 36.72 & $27.78-44.52$ \\
\hline Total & 384 & 141 & $36.72 \%$ & $31.88-41.56$ \\
\hline
\end{tabular}

Table 4. Prevalence of fasciolosis in live cattle based on breed

\section{Breed Sample size Positive Prevalence (\%)* 95\% CI}

\begin{tabular}{lllll}
\hline Local & 354 & 123 & 34.74 & $29.76-39.73$ \\
Cross & 30 & 18 & 60 & $41.39-78.60$ \\
\hline Total & 384 & 141 & 36.72 & $31.88-41.56$ \\
\hline$*$ * =Significant $(\mathrm{P}<0.05)$ & & &
\end{tabular}

Significant difference was observed in the prevalence of fasciolosis among different age groups $(\mathrm{P}<0.05)$. The highest prevalence being in age groups between 1 to 5 years of age (young adult) and lowest prevalence was recorded in animals above 5 years age (old) (Table 5).

Table 5. Prevalence of fasciolosis in live cattle based on Age groups

\begin{tabular}{lcclc}
\hline Age & Sample size & Positive & Prevalence $(\%)^{*}$ & $95 \%$ CI \\
\hline$<$ or=1 year (calf) & 46 & 11 & 23.91 & $11.10-36.72$ \\
$>1-5$ year (Adult & 138 & 61 & 44.20 & $35.81-52.59$ \\
young) & & & & \\
$>5$ years (old) & 200 & 69 & 34.5 & $27.85-41.15$ \\
\hline Total & 384 & 141 & 36.72 & $31.88-41.56$ \\
\hline
\end{tabular}

$*=$ Significant $(\mathrm{P}<0.05)$ 
Table 6. Prevalence of fasciolosis in live cattle based on body condition

\begin{tabular}{lllll}
\hline Body condition & $\begin{array}{l}\text { Sample } \\
\text { size }\end{array}$ & Positive & $\begin{array}{l}\text { Prevalence } \\
(\%)\end{array}$ & $95 \%$ CI \\
\hline Good & 205 & 75 & 36.58 & $29.94-43.24$ \\
Poor & 179 & 66 & 36.87 & $29.74-44.00$ \\
\hline Total & 384 & 141 & 36.72 & $31.88-41.56$ \\
\hline
\end{tabular}

Table 7. Prevalence of fasciolosis in live cattle on sex basis

\begin{tabular}{lllll}
\hline Sex & Sample size & Positive & $\begin{array}{l}\text { Prevalence } \\
(\%)\end{array}$ & $95 \%$ CI \\
\hline Female & 225 & 84 & 37.33 & $30.96-43.7$ \\
Male & 159 & 57 & 35.84 & $28.31-43.38$ \\
\hline Total & 384 & 141 & 36.72 & $31.88-41.56$ \\
\hline
\end{tabular}

The body condition results indicate that there was no statistically significant difference between animals having good and poor body condition $(\mathrm{P}>0.05)$ (Table 6). There was no statistically significant difference in the prevalence of fasciolosis between female and male animal $(\mathrm{P}>0.05)$ (Table 7).

\section{Discussion}

The present study proves that the prevalence of bovine fasciolosis in cattle slaughtered at Bahir Dar municipality abattoir is high (39.95\%). This result is relatively higher when compared with the prevalence $(27.1 \%)$ reported by Rahmeto Abebe (1992) in Woliso, (28.63\%) by Mulugeta Birhane (2008) at Hawassa. But it is lower than (90.65\%) reported by Yilma Jobre and Mesfin Ali (2000) at Gondar abattoir and (46.58\%) Tadele Tolossa and Worku Tigre (2007) at Jimma abattoir. This great variability shown is probably due to the ecological and climatic differences between different locations throughout the country. One of the most important factors that influence the occurrence of fasciolosis in an area is availability of the suitable snail habitat (Soulsby, 1982; Urquhart et al., 1996). In the current work, no significant variation $(\mathrm{P}>0.05)$ was observed in the prevalence of fasciolosis whether the animal slaughtered is in a poor or good body condition. This could be because body condition deterioration in cattle is manifested when fasciolosis reaches its chronic stage as (Solomon Woldemariam and Abebe Wossene, 2007). 
Both species of Fasciola were identified during the study period; however, $F$. hepatica was the most prevalent $(89.70 \%)$ species compared to $F$. gigantica $(3.63 \%)$ and mixed infection (6.67\%). This finding is higher when compared with that of Tadele Tolossa and Worku Tigre (2007) at Jimma Abattoir, Yilma Jobre and Mesfin Ali (2000) at Gondar. In Ethiopia F. hepatica and F. gigantica infections occur in areas above 1800 m.a.s.l. and below 1200 m.a.s.l., respectively. The high prevalence of rate of $F$. hepatica may be associated with the existence of favorable ecological biotopes for $L$. truncatula. Relatively small proportion of cattle were found infected with $F$. gigantica alone or mixed infection with both species. Flood prone areas and draining ditches are favorable habitats to $L$. natalensis (Urquhart et al., 1996).

Out of the total 384 fecal samples examined, $141(36.72 \%)$ were found to be positive for eggs of Fasciola species. This result is very close to the findings of (37.2\%) by Solomon Woldemariam and Abebe Wossene (2007) in Mecha \& Fogera and (33.42\%) by Yilma Jobre and Mesfin Ali (2000) in Gondar.

This study also revealed that there is no significant difference $(\mathrm{P}>0.05)$ among the different localities with respect to the prevalence of Fasciola eggs. This could be attributed to the presence of large marshy and/or water logged areas and similarity of agro-ecological conditions such as altitude, rainfall and temperature favouring the development of intermediate hosts and the parasite stages.

Analysis of the fecal egg detection result didn't show statistically significant difference between two sexes as risk factor $(\mathrm{P}>0.05)$. This indicates that there is no difference in acquiring Fasciola infection between male and female animals (Solomon Woldemariam and Abebe Wossene, 2007). This might be due to common exposure to a similar Fasciola contaminated pasture land by both sex groups and traditionally animals are driven to pasture regardless of sex.

In this study, a significant variation $(\mathrm{P}<0.05)$ was revealed in the prevalence of Fasciola between different age groups. This finding well agrees with the works of Solomon Woldemariam and Abebe Wossene (2007); and Yilma Jobre and Mesfin Ali, 2000. The detections of Fasciola eggs was lower in the calf group $(<1$ years age). This is attributed to the fact that calves are not often driven with older age groups to grazing and watering points. They are kept at a nearby village where the source of feeding is much limited. This practice naturally reduces the chance of 
exposure in this age class. In different parts of Ethiopia, similar results indicating inverse correlation of prevalence and age of cattle were reported by Rahmeto Abebe (1992). As the age increased to the adult stage, i.e. second group ( $>1-5$ years of Age), the magnitude of infection rate increased to a higher level. As the age of the animal increases, the possibility of being exposed to Fasciola increases and hence high prevalence of fasciolosis was observed. The reason for significantly high prevalence of fasciolosis $(\mathrm{P}<0.05)$ in cross breed compared to local breed could be due to lower resistance of cross than local breed.

\section{Conclusion and Recommendation}

In general fasciolosis was found prevalent in the study areas. This will be a hindrance to the livestock production by causing remarkable direct or indirect losses in the study areas. Moreover, the study area is suitable for the survival of the snail which worsened the situation for the future. Therefore, strategic application of fluckicide and avoiding animals grazing from marshy land plays considerable success for the control of fasciolosis in these study areas.

\section{Acknowledgment}

The authors gratefully acknowledge the generous assistance by meat inspection personnel at Bahir Dar Abattoir and owners of the animals and Bahir Dar regional veterinary laboratory.

\section{References}

Abebe R., 1992. Fasciolosis clinical occurrence, coprological, Abattoir and snail survey in and around Woliso. DVM Thesis, Faculty of Veterinary Medicine, Addis Ababa University.

Asfaw, L., 2008. Bovine Fasciolosis: Carpological, abattoir survey and it is economic impact due to liver condemnation at Soddo municipality abattoir. DVM Thesis, Faculty of Veterinary Medicine, Hawassa University, Hawassa, Ethiopia.

Asrat M., 2004. Infection prevalence of bovine Fasciolosis in irrigation schemes along the upper Awash River Basin and effects of strategic anthelmintic treatment in selected up stream areas. MSc Thesis, Department of Biology, Addis Ababa University. 
Birhane, M., 2008. Bovine Fasciolosis, in animals slaughtered at Hawassa municipality Abattoir: coprology, Abattoir survey and Economic loss Assessment due to liver condemnation. DVM Thesis, Faculty of Veterinary Medicine, Hawassa University, Hawassa, Ethiopia.

BOA, 2000. Livestock population of Amhara region. A document of the Animal health team. Bureau of agriculture, Amhara National Regional State, Bahir Dar.

DACA, 2006. Standard Veterinary Treatment Guideline for Veterinary practice $1^{\text {st }}$ ed. Drug Administration and control Authority of Ethiopia.

Hansen, J. and Perry, B., 1994. The epidemiology, diagnosis and control of helminths parasites of ruminants. A hand book, International laboratory for Research on Animal Disease. Nairobi, Kenya, pp. 31-36.

Hunter, A., 1994. Fasciolosis. In: animal health. Specific diseases in the Tropics. $1^{\text {st }}$ eds. CTA. Vol.2 Macmillan, London. Pp. 149-154.

Jobre, Y. and Ali, M., 2000. Dry season bovine Fasciolosis in North Western part of Ethiopia. Revue, Med. Vet., 151, 493-500.

Jobre, Y. and Malone, J.B., 1998. A geographic information system forecast model for control of fasciolosis in Ethiopia. Vet. Parasitol. 78, 103-127.

Malone, J.B., Gommes, R., Hansen, J., Jobre Y., Slingenbergh, J., Snijders, F., Nachet, O.F. and Ataman, E., 1989. Geographical information system on the potential distribution and abundance of $F$. hepatica and F. gigantica in East Africa based on food and agriculture organization data bases. Vet. Parasitol., 78, 87-101.

Radostits, O. M., Blood D.C. and Gay, C.C., 1994. Disease caused by helminthic parasite In: Veterinary Medicine in text book of the disease of cattle, sheep, pigs, goats and horses $8^{\text {th }}$ ed. Bailliere Tindall, London Pp. 1230-1235.

Rapsch, C., Auer, C., Deplazer, P., Braun, U. And Torgerson, 2006. Estimating the true prevalence of F.hepatica in cattle slaughtered in Switzerland in the absence of absolute diagnostic test. Intern. J. Parasitol. 36, 1153-1158.

Soulsby, E.J.L., 1982. Helminthes, Arthropods and Protozoa's of Animals. $7^{\text {th }}$ eds. Bailliere Tindall, London, pp 136-161.

Thrusfield, M., 1995. Veterinary epidemiology $2^{\text {nd }}$ ed. Blackwell Science Ltd. PP 117-198.

Tolossa, T. and Tigre W., 2007. The prevalence and economic significance of Bovine Fasciolosis at Jimma Abattoir, Ethiopia. The internet J.Vet. Med.3, 15.

Troncy, P.M., 1989. Helminths of livestock and poultry in tropical Africa. In: Fischer. Manual of Tropical Veterinary Parasitology. CAB International, UK. Pp. 63-73. 
Urquhart, G.M., Armour, J., Duncan, J.L., Dunn, A.M. and Jennings, F.W., 1996. Veterinary parasitology. $2^{\text {nd }}$ ed. Oxfords, Longman: Scientific and technical press, UK. pp. 102-113; 115-120

Wamae, L. W., Hammond. J. A., Harrison L.J.S. and Onyango-Abuje. J.A., 1998. Comparison of production losses caused by chronic Fasciola gigantica infection in yearling Friesian and Boran cattle. Trop. Anim. Hlth. Prod., 30, 23-30.

Woldemariam, S. and Wossene, A., 2007. Effects of a strategic anthelmintic treatment intervention bovine Fasciolosis: A study conducted in facilities endemic area in north western Ethiopia, Ethiop. Vet. J., 11(2), 59-68. 